University of Nebraska - Lincoln

DigitalCommons@University of Nebraska - Lincoln

2014

STEVENALTICA, A NEW GENUS OF MOSS AND LEAF-LITTER

INHABITING FLEA BEETLES FROM BOLIVIA (COLEOPTERA:

CHRYSOMELIDAE: GALERUCINAE: ALTICINI).

Alexander S. Konstantinov

Adelita M. Linzmeier

Vilma P. Savini

Follow this and additional works at: https://digitalcommons.unl.edu/usdaarsfacpub

This Article is brought to you for free and open access by the U.S. Department of Agriculture: Agricultural Research Service, Lincoln, Nebraska at DigitalCommons@University of Nebraska - Lincoln. It has been accepted for inclusion in Publications from USDA-ARS / UNL Faculty by an authorized administrator of DigitalCommons@University of Nebraska - Lincoln. 
PROC. ENTOMOL. SOC. WASH. 116(2), 2014, pp. 159-171

\title{
STEVENALTICA, A NEW GENUS OF MOSS AND LEAF-LITTER INHABITING FLEA BEETLES FROM BOLIVIA (COLEOPTERA: CHRYSOMELIDAE: GALERUCINAE: ALTICINI).
}

\author{
Alexander S. Konstantinov, Adelita M. Linzmeier, and Vilma P. Savini
}

(ASK) Systematic Entomology Laboratory, USDA, ARS, c/o Smithsonian Institution, P.O. Box 37012, National Museum of Natural History, Washington, DC 20013-7012, USA (alex.konstantinov@ars.usda.gov); (AML) Faculdade de Ciências Biológicas e Ambientais, Universidade Federal da Grande Dourados. Caixa Postal 322, 79804-980 Dourados, Mato Grosso do Sul, Brazil (alinzmeier@yahoo.com.br); (VPS) Museo del Instituto de Zoologia Agricola, Facultad de Agronomia, Universidad Central de Venezuela, Maracay 2101-A Estado Aragua, Venezuela (vsgioia@gmail.com)

Abstract.-A new genus, Stevenaltica, with two new species, S. normi and S. erronis, from Bolivia is described and illustrated. It is similar to Exoceras Jacoby. An identification key for all flea beetle genera known to occur in mosses in the Western Hemisphere is provided.

Key Words: Bryobionts, key to genera, Neotropics

DOI: $10.4289 / 0013-8797.116 .2 .159$

Until recently, 27 flea beetle species from 14 genera (Coleoptera: Chrysomelidae: Galerucinae: Alticini) (Konstantinov et al. 2013) are documented to live within moss cushions. Nineteen species from nine genera were known in the Eastern Hemisphere and eight species from five genera in the Western Hemisphere. Recent beetle explorations in Bolivia, including mossinhabiting beetles revealed a previously unknown genus and two species of flea beetles that are described below. This brings the number of genera of mossinhabiting flea beetles to 15 and the number of species to 29 .

In addition to being found in moss, this new genus was also collected in leaf litter, which is not uncommon for mossliving flea beetles. A few other genera exhibit similar habitat preferences, e.g., Benedictus Scherer 1989 and Paraminota
Scherer 1989, both occurring in Asia. So far the only leaf litter inhabiting flea beetle genera found in the New World are Andersonaltica Linzmeier and Konstantinov 2012 and Deciplatus Linzmeier and Konstantinov 2009, both belonging to the Monoplatina and differ dramatically from the genus described below in having globosely swollen last meso-and metatarsomeres. Moss and leaf litter inhabiting flea beetles are among the smallest leaf beetles (Chrysomelidae), with reduced hind wings, greatly simplified and shortened meso- and metathorax, and the elytra lacking humeral calli.

\section{Materials And Methods}

Initially, moss samples were collected in the field from tree branches, trunks and rocks and were placed directly in Berlese funnels for beetle extraction. However by 
the end of the collecting trip it became clear that there was not enough time to process all the collected moss through Berlese funnels. Therefore, moss samples were sifted, which dramatically reduced the size of the remaining substrate which was put into Berlese funnels. It remains unclear if sifting causes loss of beetle specimens. Moss-sifting at two sites did not yield any flea or leaf beetles: Achira (Santa Cruz Dept., Florida Prov., Vicoquin area above Achira, road to Amboró, $18^{\circ} 07^{\prime} \mathrm{S}, 63^{\circ} 48^{\prime} \mathrm{W}, 2000-2100 \mathrm{~m}, 25$. XI.2013) and on road between Villa Tunari and Cochabamba (Cochabamba Dept., Chaparé Prov., Highway 4, 75 km SW of Villa Tunari, 2375m, $17^{\circ} 12.23^{\prime} \mathrm{S}$, 6551.51'W, 10.XII.2013).

Dissecting techniques, measurements, and terminology follow Konstantinov (1998). Observations were made with a Zeiss Discovery V20 microscope and digital images were taken with an AxioCam HRC digital camera attached to it. Habitus illustrations were produced after a technique described in Litwak and Harel (2013). The habitus drawing of Stevenaltica normi was done with the pronotum of the beetle bent down slightly which changed its visible proportions. Specimens are deposited in the Museo de Historia Natural Noel Kempff Mercado, Universidad Autonoma "Gabriel Rene Moreno", Santa Cruz, Bolivia (MNKB), National Museum of Natural History, Smithsonian Institution, Washington DC, USA (USNM) and Collection of the Canadian Museum of Nature, Ottawa, Canada (CMNC).

\section{Results AND Discussion}

Stevenaltica Konstantinov, Linzmeier and Savini, new genus

(Figs. 1-24)

Description.-Body (Figs. 1-4, 16, 17) length $1.62-1.83 \mathrm{~mm}$, width $0.80-0.97 \mathrm{~mm}$, elongate, weakly convex in lateral view (2.6 times as long as high). Color from pale brown to dark brown, with appendages lighter, males generally darker.

Head (Figs. 5, 20) prognathous, slightly convex in lateral view. Frons and vertex forming slightly curved straight line (Figs. 3, 17) in lateral view. Supraorbital pore well developed. Antennal callus drop-shaped. Midfrontal sulcus deep, short. Suprafrontal sulcus shallower than midfrontal. Supracallinal sulcus evenly deep, slightly convex with sharp margins. Suprantennal sulcus visible, shallower than supracallinal. Orbital sulcus continuous with supracallinal, as deeply impressed. Supraorbital sulcus shallow, poorly deliniated. Subgenal suture shallow along base of mandible. Orbit 1.6 times as wide as transverse diameter of antennal socket in frontal view. Interantennal space as wide as transverse diameter of antennal socket in frontal view. Frontal ridge relatively narrow, as wide as antennal socket in frontal view, much wider between antennal sockets than near anterofrontal ridge, where it is blade-shaped. Anterofrontal ridge very low, not separated from frontal ridge, its surface covered with large poorly defined wrinkles. Eyes small, weakly protruding laterally. Labrum with four setiferous pores situated symmetrically, apical margin solid. Labial palpus with three palpomeres. Maxillary palpus with four palpomeres, apical palpomere much smaller than penultimate. Antenna with 11 antennomeres.

Pronotum (Figs. 5, 20) 1.1 times wider than long (measured across widest point), with antebasal transverse impressions merging with its sides. Sides slightly sinusoidal and relatively narrowly explanate. Pronotum gradually widening from base to apical one third, converging to apex. Anterolateral callosity angular, with anterior pore situated near middle. 


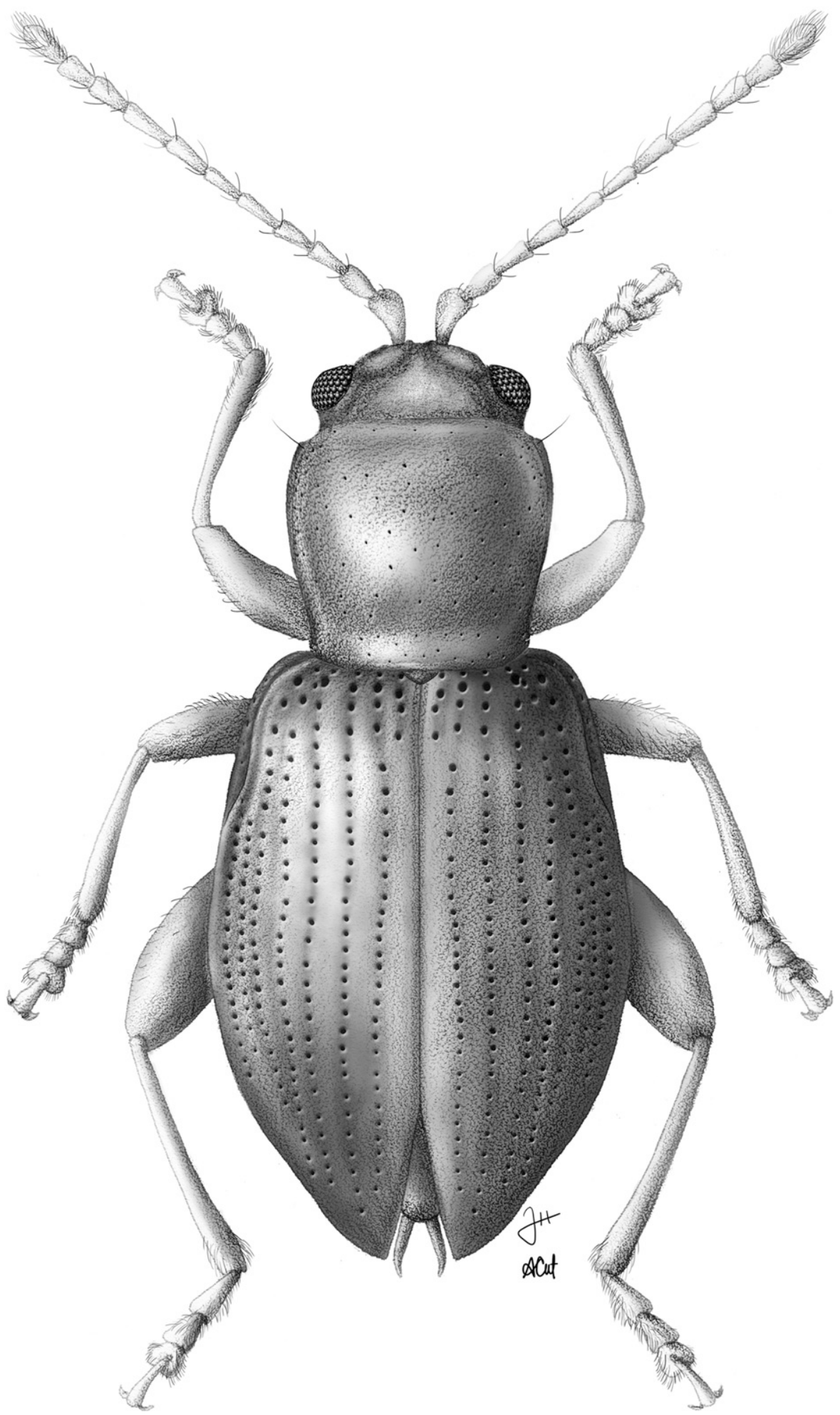

Fig. 1. Stevenaltica normi, dorsal habitus. 


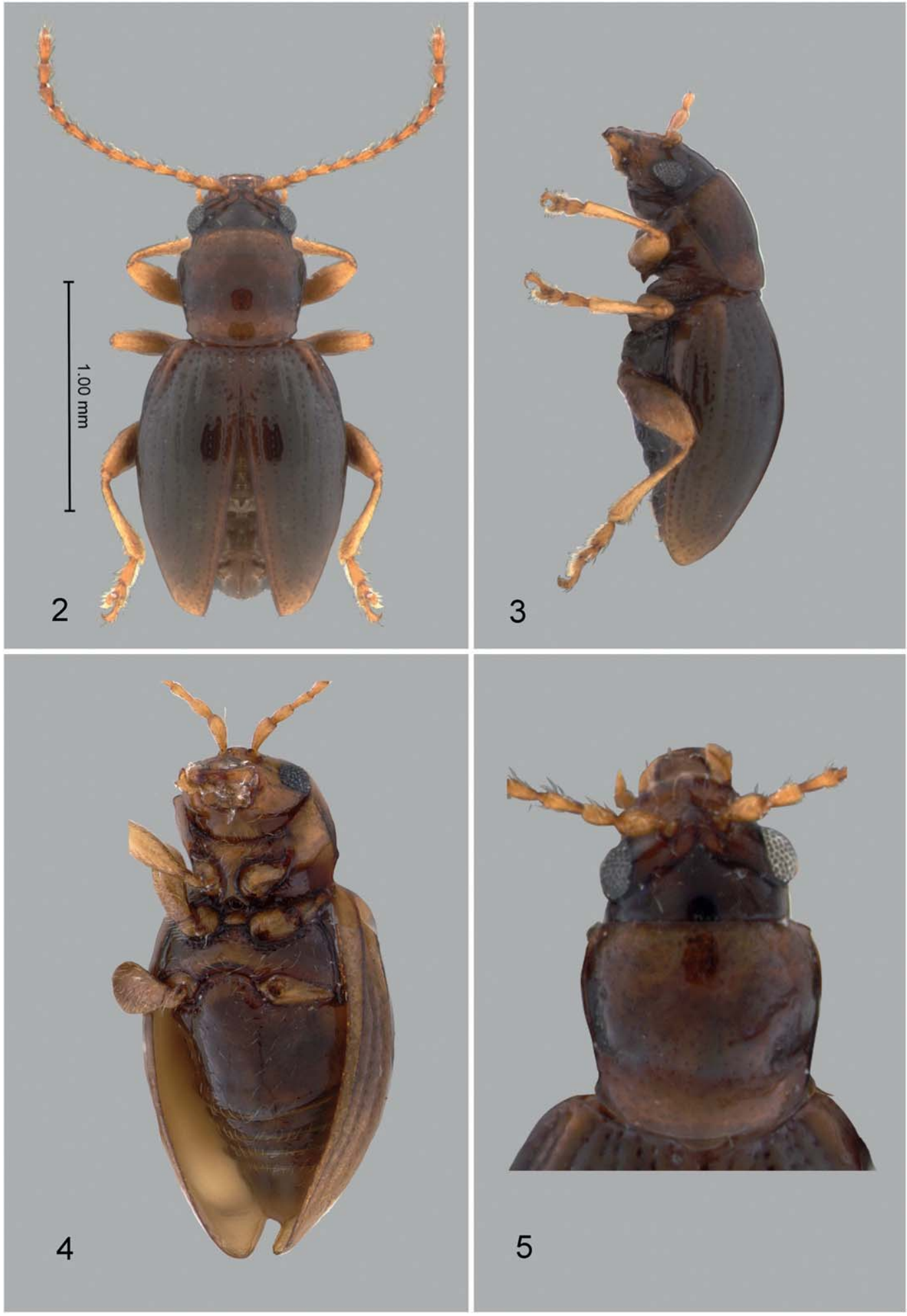

Figs. 2-5. Stevenaltica normi. 2, Dorsal view. 3, Lateral view. 4, Ventral view. 5, Pronotum, dorsal view. 

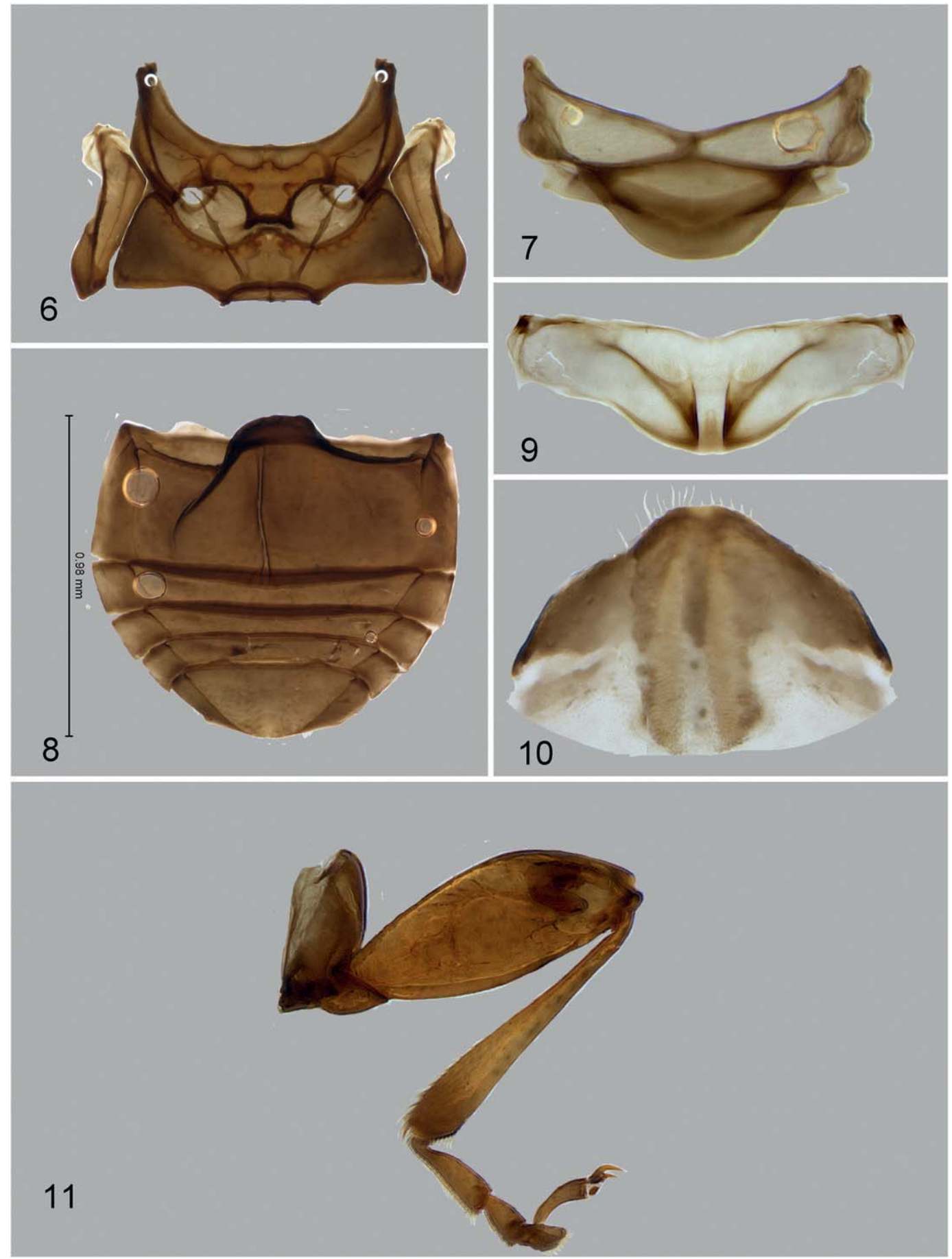

Figs. 6-11. Stevenaltica normi. 6, Meso- and metasternum. 7, Mesonotum. 8, Abdominal ventrites. 9, Metanotum. 10, Apical abdominal tergite. 11, Hind leg. 


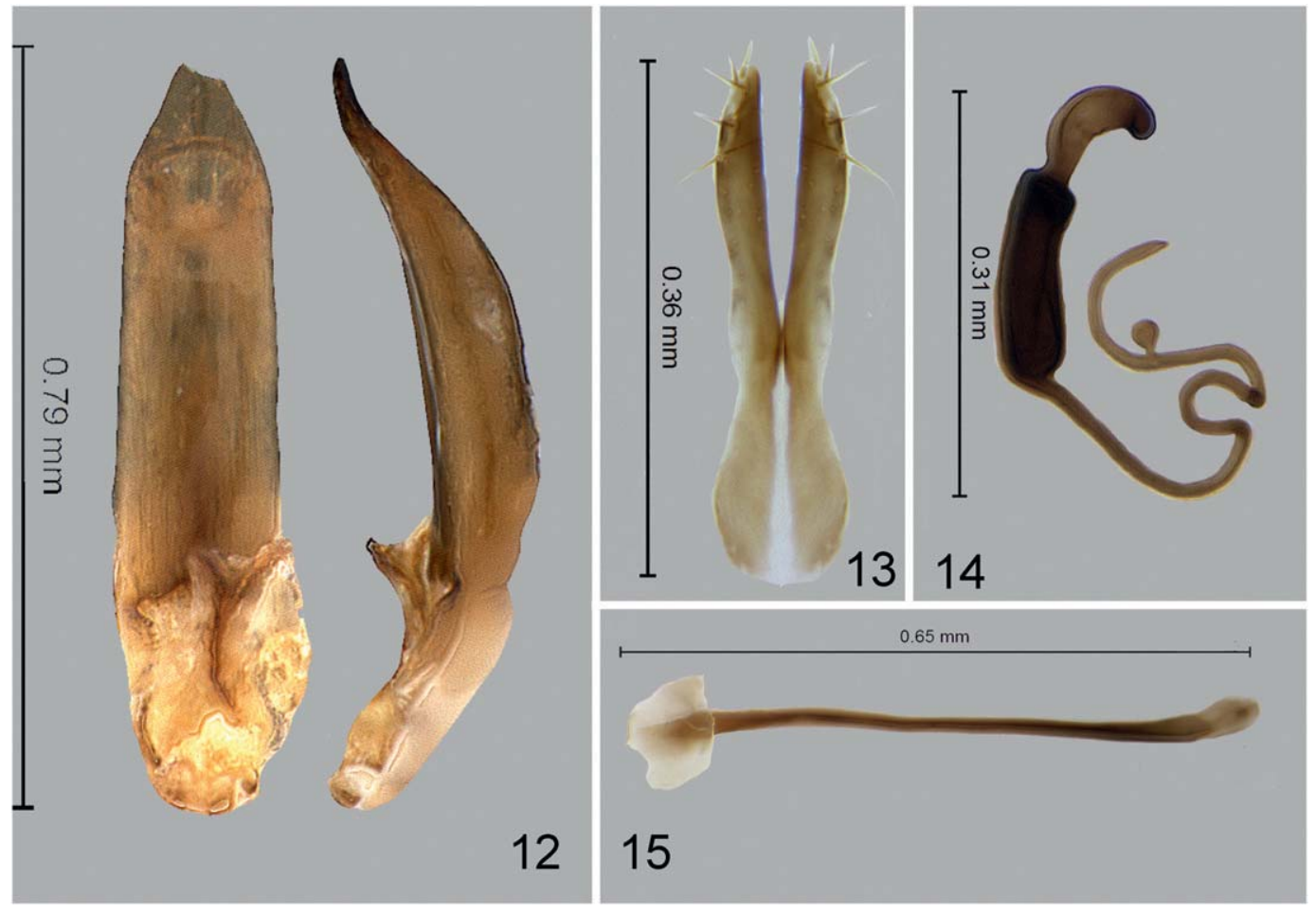

Figs. 12-15. Stevenaltica normi. 12, Median lobe of aedeagus, ventral and lateral view. 13, Vaginal palpi. 14 , Spermatheca. 15 , Tignum.

Posterolateral callosity protruding laterally. Basal margin evenly convex, with distinct border. Anterior coxal cavity open. Intercoxal prosternal process more or less flat in middle, abruptly widening at apex, concave, projecting beyond procoxae (Fig. 4).

Mesoscutellum short, broadly rounded (Fig. 7). Mesocoxae separated by both meso- and metasterna. Mesosternal intercoxal process (Fig. 6) with sides converging, broadly concave on top. Mesepisternum much broader than mesepimeron.

Metanotum greatly simplified (Fig. 9), consisting only of sclerotized allocrista. Metasternum (Fig. 6) as long as mesosternum. Metendosternite with short and wide stalk and long, thin arms narrowing abruptly after tendon attachments.
Elytron (Figs. 2, 4, 16) with maximum width near middle. Humeral callus absent. Sharp ridge situated lateral of fifth elytral stria. Punctural rows six and seven do not reach base of elytron. Elytral apex narrowly rounded. Epipleura relatively broad (Fig. 4), inwardly oblique, not reaching sutural margin of elytron. Hind wings absent.

Profemur more or less cylindrical, 3.5 times as long as wide. Mesofemur more flat than profemur, 3.4 times as long as wide. Metafemur weakly swollen, without hump on anterolateral margin (Fig. 11 ), about 2.8 times as long as wide. Proand mesotibiae round in cross section, with apical spine. Metatibia (Fig. 13) straight in dorsal view, slightly curved in lateral view, convex dorsoventrally, with small, oblique flat area at apex, without 


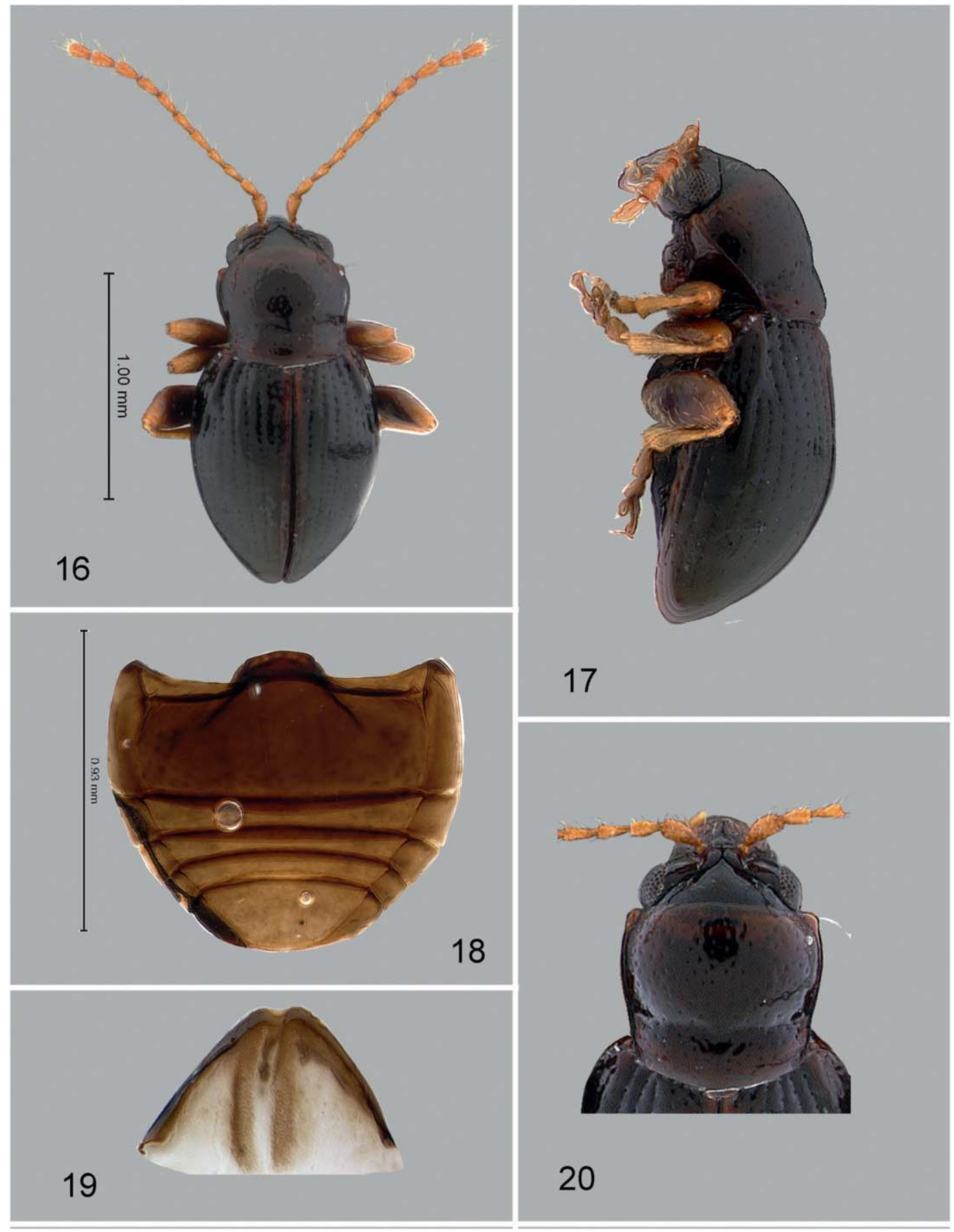

Figs. 16-20. Stevenaltica erronis. 16, Dorsal view. 17, Lateral view. 18, Abdominal ventrites. 19, Apical abdominal tergite. 20, Pronotum, dorsal view. 


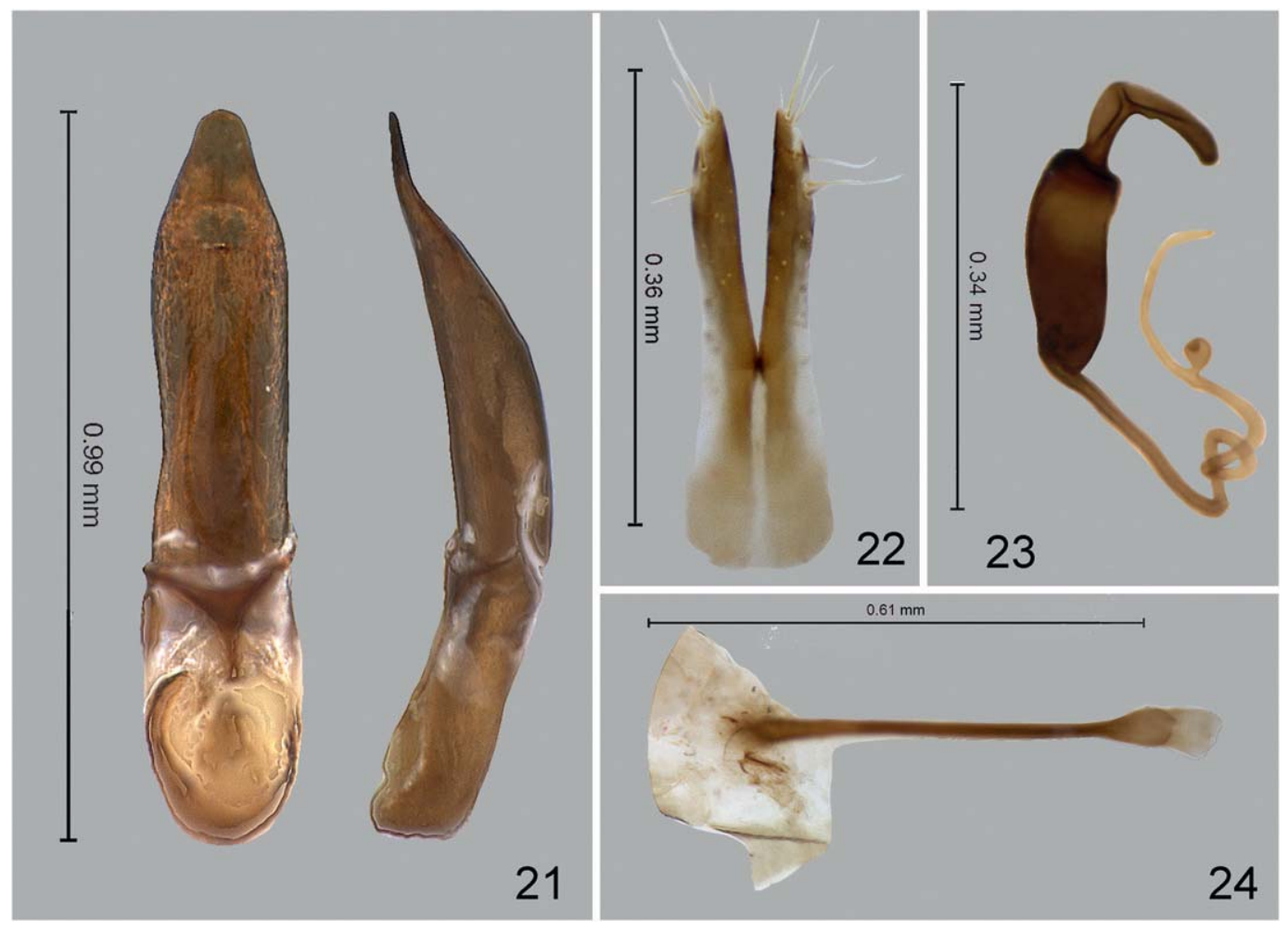

Figs. 21-24. Stevenaltica erronis. 21, Median lobe of aedeagus, ventral and lateral view. 22, Vaginal palpi. 23, Spermatheca. 24, Tignum.

serration on outer edge and without preapical excavations on both inner and outer edges; apical spur shorter than tarsal claw. Claw appendiculate.

Abdomen with five distinctly visible sternites (Figs. 8, 18). Apical sternite slightly shorter than three preceding sternites combined, with appendages basally. Basal sternite without longitudinal ridge. Apical tergite of female nearly triangular, unevenly covered with long setae, sclerotized posteriorly, with elongate membranous window in middle (Figs. 10, 19). Spermatheca (Figs. 14, 23) with receptacle sharply separated from pump. Basal, pre-gland part of duct with coils, longer than post-gland part. Tignum (Figs. 15, 24) widening anteriorly. Vaginal palpi (Figs. 13, 22) slender, strongly sclerotized, more narrowly separated anteriorly than posteriorly.
Median lobe of aedeagus (Figs. 12, 21) simple, dorsally flattened, weakly convex in lateral view, without much sculpture ventrally, without membranous window.

Type species.-Stevenaltica normi Konstantinov, Linzmeier, Savini

Etymology.-This genus is named after Steve Lingafelter who organized numerous beetle collecting expeditions to Bolivia including the one, which yielded this remarkable new flea beetle genus. The name is feminine.

Remarks.-Stevenaltica does not fit within the existing key to Neotropical flea beetle genera (Scherer 1983). Having the antebasal groove at the base of the pronotum merging with the sides, a well developed scutellum, elytral punctures arranged into nine distinct rows, and angular anterolateral corners of the pronotum, Stevenaltica ends up in a group 
of obviously different genera (Chorodecta Harold, Calliphron Jacoby, and Orodes Jacoby). They are much larger in size, have longer and wider elytra in comparison to the pronotum and the antebasal groove of the pronotum is much shallower. The head in Calliphron and Orodes in lateral view is strongly angulate (it is evenly convex in Stevenaltica). In Chorodecta, the head is nearly round in shape with huge antennal calli (it is elongate with moderately sized antennal calli in Stevenaltica).

Among Neotropical flea beetle genera, Stevenaltica is most similar to Exoceras Jacoby. They have similar body size and proportions, open procoxal cavities, generally the same set of head sulci, and similar proportions of the antenno- and tarsomeres. Stevenaltica is obviously different from Exoceras by the following characters: pronotal base evenly convex (extended into a lobe in Exoceras), angular anterolateral corners of the pronotum (they are obliquely elongate in Exoceras), vertex and frons in lateral view evenly and weakly convex (strongly convex and angulate in Exoceras), part of head from end of labrum to supraantennal sulci about as long as vertex (it is much longer than vertex in Exoceras), and elytron with a sharp ridge lateral to fifth elytral stria (ridge is absent in Exoceras).

\section{Stevenaltica normi Konstantinov,} Linzmeier and Savini, new species (Figs. 1-15)

Description.-Body length 1.63$1.83 \mathrm{~mm}$, width $0.81-0.97 \mathrm{~mm}$. Color from pale brown to brown, slightly darker in males. Appendages and elytral apex lighter. Elytral ridge lighter than rest of elytra. Pronotum with smaller and more sparse punctures than those of S. erronis. Anterolateral callosity slightly longer than that of $S$. erronis with acute angle (Fig. 5). Vaginal palpi with posterior sclerotization only slightly narrower than anterior (Fig. 13). Spermathecal pump (Fig. 14) nearly parallel-sided, at base about as wide as at apex. Duct forming loose coil. Tignum posteriorly more or less arrow-shaped, anteriorly curved (Fig. 15). Median lobe of aedeagus nearly parallel-sided in ventral view, ventrally smooth, without longitudinal impression (Fig. 12), apex slightly curved dorsally in lateral view.

Etymology.-The specific name is dedicated to Norman Woodley who, over the years, collected some spectacular flea beetles, particularly in the West Indies (e.g., Normaltica obrieni Konstantinov 2002 and Argopistes woodleyi Blanco and Konstantinov 2013).

Ecology.-Unidentified moss samples which contained $S$. normi were collected in the forest from a variety of substrates (rocks, tree stumps, trunks and branches) (Figs. 30, 31). Specimens collected by R. Anderson were extracted from forest leaf-litter.

Material examined.-Holotype female. Labels: 1) BOLIVIA: Santa Cruz Dept. Yungas de la Siberia, $26 \mathrm{~km} \mathrm{NW}$ of Comarapa $2560 \mathrm{~m}$, moss, $17^{\circ} 49.22^{\prime} \mathrm{S}$, $64^{\circ} 40.80^{\prime} \mathrm{W}$ WP405, 26.XI.2013 leg. A. Konstantinov; 2) Holotype Stevenaltica normi n. sp. des. Konstantinov, Linzmeier, Savini, 2014 (MNKB). Paratypes: 1 male, 3 females with the same labels as holotype (USNM). Paratypes 2 females with labels: 1) BOLIVIA: Santa Cruz $26.4 \mathrm{~km} \mathrm{NW}$ Comarapa, Kara Huasi, Yungas de la Siberia, 2600m, 1749.32' S, 64 $41.17^{\prime} \mathrm{W}$, 21.I.1999 R.Anderson, mixed Yungas/ bamboo litter, 99-002A (CMNC).

\section{Stevenaltica erronis Konstantinov, Linzmeier and Savini, new species} (Figs. 16-24)

Description.-Body length 1.62$1.78 \mathrm{~mm}$, width $0.80-0.86 \mathrm{~mm}$. Color 


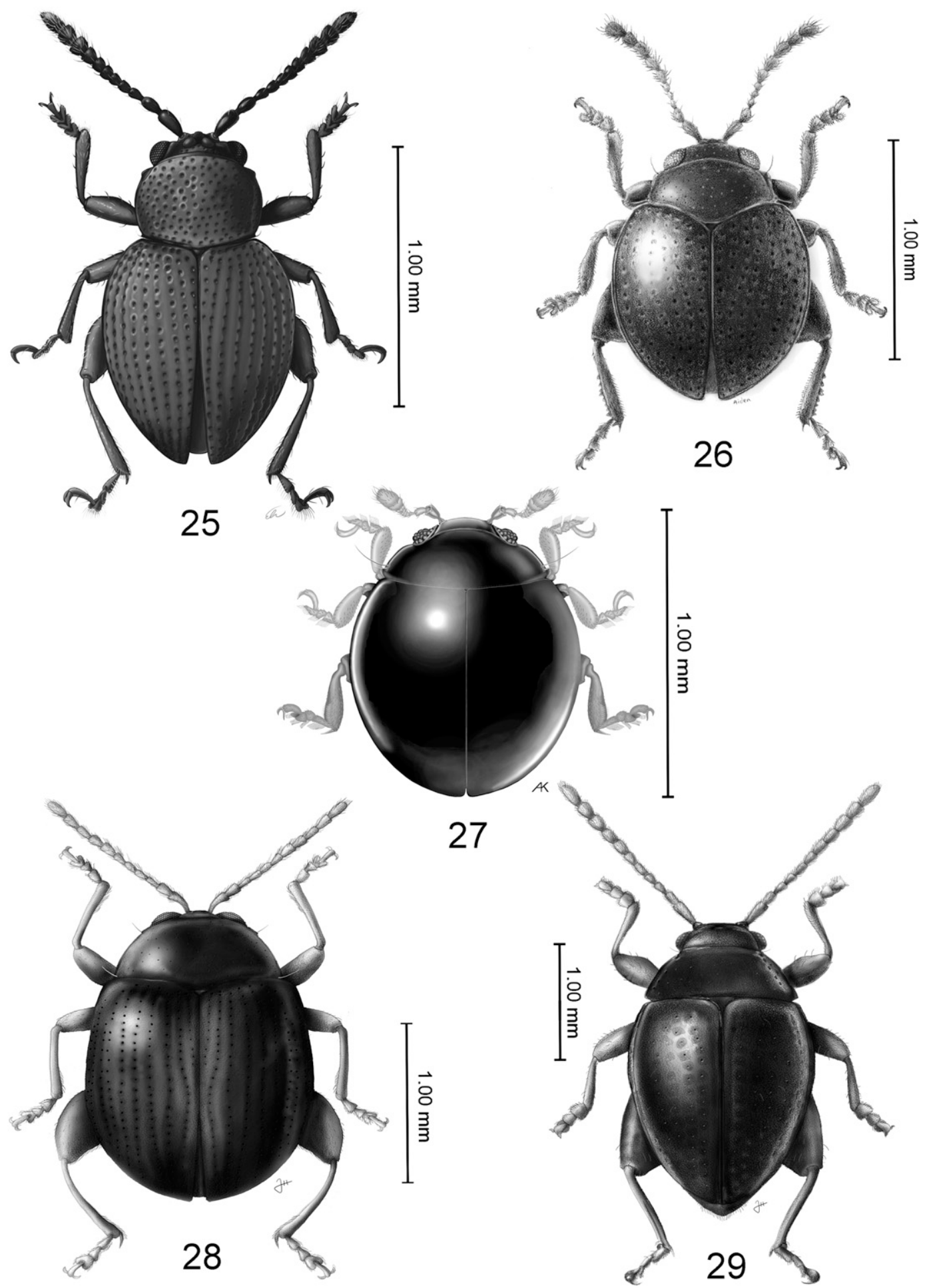

Figs. 25-29. Moss-inhabiting flea beetles of Western Hemisphere. 25, Borinken elyunque Konstantinov and Konstantinova 2011. 26, Monotalla guadeloupensis Bechyné 1956. 27, Kiskeya baorucae Konstantinov and Chamorro-Lacayo 2006. 28, Nicaltica selvanegra Konstantinov et al. 2009, Ulrica eltoro Konstantinov and Konstantinova 2011. 


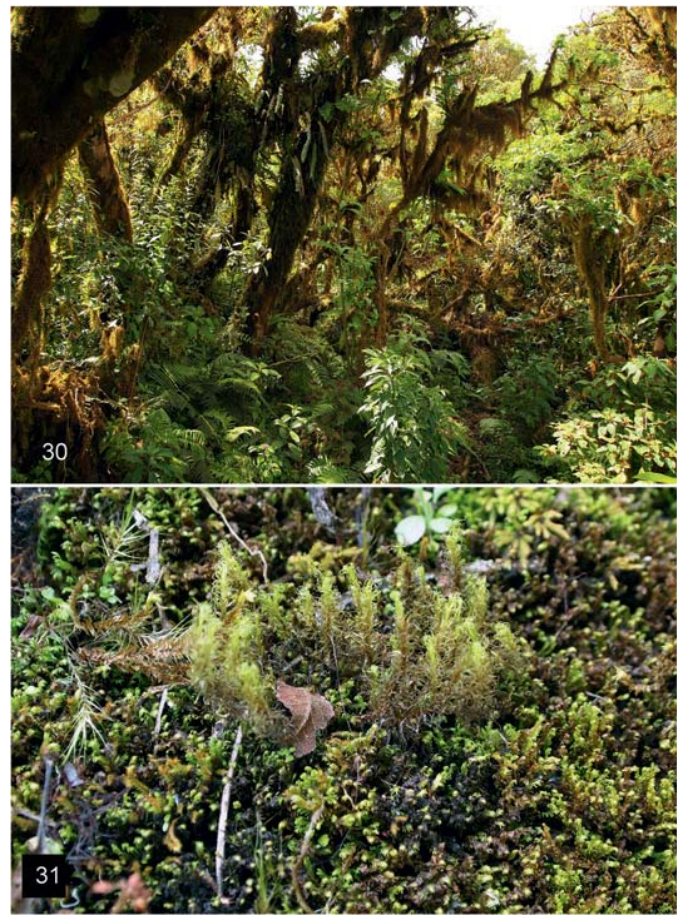

Figs. 30, 31. Habitats of Stevenaltica normi. 30, Forest at Yungas de la Siberia, Santa Cruz, Bolivia. 31, Moss cushions at Yungas de la Siberia.

dark brown, slightly darker in males. Antennae and apices of femora and remainder of legs lighter. Bases of femora dark brown. Elytral ridge as dark as remainder of elytron. Pronotum with larger and denser punctures than those of $S$. normi. Anterolateral callosity angulate, evenly curved without acute angle (Fig. 20). Vaginal palpi with posterior sclerotization much narrower than anterior (Fig. 22). Spermathecal pump (Fig. 23) widening apically, at base narrower than at apex, duct forming compact coil. Tignum posteriorly shaped amorphously, anteriorly straight (Fig. 24). Median lobe of aedeagus slightly narrower in middle than apically and basally in ventral view, ventrally with dense longitudinal wrinkles, with longitudinal impression (Fig. 21 ), apex straight in lateral view.
Etymology.-The species names erronis means abandoned in Latin and refers to Steve getting lost in the forest at least twice on the trip to Bolivia in November-December 2013. It is a noun in apposition.

Ecology.-Unidentified moss samples, which contained $S$. erronis were collected in the forest from a variety of substrates (rocks, tree stumps, trunks and branches).

Material examined.-Holotype female. Labels: 1) BOLIVIA: Cochabamba Dept., Chaparé Prov., Highway 4, 7.4 km N of north end of Laguna Corani $2865 \mathrm{~m}$, moss, $17^{\circ} 10.37^{\prime} \mathrm{S} 65^{\circ} 53.67^{\prime} \mathrm{W}$ WP433, 12 Dec 2013 leg. A.Konstantinov; 2) Holotype Stevenaltica erronis n. sp. des. Konstantinov, Linzmeier, Savini, 2014 (MNKB). Paratype male, with same label as holotype (USNM).

\section{Key to Stevenaltica species}

1. Elytral ridge paler than rest of elytra. Median lobe of aedeagus without dense longitudinal wrinkles and longitudinal impression ventrally and apex curved dorsally in lateral view (Fig. 12). Spermathecal duct forming loose coil (Fig. 14) . . . . ... Stevenaltica normi Konstantinov et al. Elytral ridge as dark as rest of elytra. Median lobe of aedeagus with dense longitudinal wrinkles and longitudinal impression ventrally and apex straight in lateral view (Fig. 21). Spermathecal duct forming tight coil (Fig. 23) . . . . . . . . . . Stevenaltica erronis Konstantinov et al.

Key to moss-inhabiting flea beetle genera of the Western Hemisphere

1. Antennae with apical antennomeres distinctly wider than mid antennomeres, forming distinct club .......... Kiskeya Konstantinov and ChamorroLacayo 2006 (Fig. 27) 
- Antennae with apical antennomeres as wide or only slightly wider than mid antennomeres, not forming distinct club ... 2

2(1). Antennae with 10 antennomeres ...... . . . Monotalla Bechyné 1956 (Fig. 26)

- Antennae with 11 antennomeres . . . . 3

3(2). Base of pronotum with transverse groove ..... Stevenaltica Konstantinov et al. (Fig. 1)

- Base of pronotum without transverse groove..............

4(3). Apical metatarsomere globosely swollen, much larger than apical protarsomere . . . . . . . U Ulrica Scherer 1962 (Fig. 29)

- Apical metatarsomere not swollen, about as wide as apical protarsomere .....5

5(4). Vertex, pronotum and elytra covered with large punctures, their diameter is much larger than distance between punctures. Frontal ridge distally narrower than between antennal sockets. Pronotum distally nearly as wide as basally. . . . . . . ........ Borinken Konstantinov and Konstantinova 2011 (Fig. 25)

- Vertex, pronotum and elytra covered with small punctures, their diameter is much smaller than distance between punctures. Frontal ridge distally wider than between antennal sockets. Pronotum distally much narrower than basally. . . . . . . . . . . . Nicaltica Konstantinov et al. 2009 (Fig. 28)

\section{AcKnowledgments}

We thank S. W. Lingafelter, N. E. Woodley and T. Henry (Systematic Entomology Laboratory, Washington D.C.) for companionship during the collecting trip to Bolivia. We are grateful to R. Anderson (Canadian Museum of Nature, Ottawa, Canada) for spectacular flea beetle collecting over the years that yielded an entirely unknown leaf-litter inhabiting flea beetle fauna in the Neotropics. K. D. Prathapan (Kerala Agricultural University, Kerala, India) and N. E. Woodley reviewed an earlier version of the manuscript and provided valuable suggestions. We are thankful to Charlotte Hartle (Charlottesville, VA, USA) for the habitus illustration of Borinken elyunque, Jessica Hsiung (Toronto, Canada) for the habitus illustrations of Stevenaltica normi, Nicaltica selvanegra and Ulrica eltoro and Aiden Jimeno (Twinbrook, MD, USA) for the habitus illustration of Monotalla guadeloupensis. Amy Cutler (Washongton DC) edited a habitus illustration of Stevenaltica normi.

\section{Literature Cited}

Bechyné J. 1956. Über die Alticiden-Sammlung Heikertinger (Col. Phytophaga). Entomologische Arbeiten aus dem Museum G. Frey Tutzing bei München 7(2): 577-598.

Blanco, J. and A. S. Konstantinov. 2013. Review of the New World species of the genus Argopistes Motschulsky (Coleoptera: Chrysomelidae: Galerucinae: Alticini). Zootaxa 3626(2): 249267. doi:10.11646/zootaxa.3626.2.3

Konstantinov, A. S. 1998. Revision of the Palearctic species of Aphthona Chevrolat and cladistic classification of the Aphthonini (Coleoptera: Chrysomelidae: Alticinae). Memoirs on Entomology, International 11: 1-429.

Konstantinov, A. S. 2002. A new genus of flea beetles from the Greater Antilles (Coleoptera: Chrysomelidae). Zootaxa 124: 1-24.

Konstantinov, A. S. and M. L. Chamorro-Lacayo. 2006. A new genus of moss-inhabiting flea beetles (Coleoptera: Chrysomelidae) from the Dominican Republic. Coleopterists Bulletin 60(4): 275-290. doi:10.1649/0010-065X (2006)60[275:ANGOMF]2.0.CO;2

Konstantinov A. S., M. L. Chamorro, K. D. Prathapan, Si-Qin Ge and Xing-Ke Yang. 2013. Moss-inhabiting flea beetles (Coleoptera: Chrysomelidae: Galerucinae: Alticini) with description of a new genus from Cangshan, China. Journal of Natural History 47(37-38): 24592477. doi:10.1080/00222933.2012.763068

Konstantinov, A. S., M. L. Chamorro-Lacayo, and V. P. Savini. 2009. A new genus of moss-inhabiting flea beetles (Coleoptera: Chrysomelidae) from Nicaragua. Coleopterists Bulletin 63(1): 1-12. doi:10.1649/1127b.1

Konstantinov, A. S. and A. A. Konstantinova. 2011. New genus and species of flea beetles 
(Coleoptera: Chrysomelidae: Galerucinae: Alticini) from Puerto Rico, with some considerations on flea beetle diversity in the Caribbean and a key to the Caribbean Monoplatini genera. ZooKeys 155: 61-87. doi:10.3897/ zookeys.155.2124

Linzmeier, A. M. and A. S. Konstantinov. 2009. A new genus of flea beetles (Coleoptera: Chrysomelidae) from the south of Brazil. Proceedings of the Entomological Society of Washington 111(3): 656-665. doi:10.4289/ 0013-8797-111.3.656

Linzmeier, A. M. and A. S. Konstantinov. 2012. A new genus of leaf litter inhabiting Neotropical Monoplatina (Coleoptera: Chrysomelidae: Galerucinae: Alticini). Zootaxa 3260: 19-32.
Litwak, T. and M. Harel. 2013. Digital-coquille technique: step by step creation of a beetle illustration. Journal of Natural History Illustration 45(4): 1-4.

Scherer, G. 1962. Bestimmungsschlussel der neotropischen Alticinen Genera (Col. Chrysom.). Entomologische Arbeiten aus dem Museum G. Frey Tutzing bei München 13(2): 497-607.

Scherer, G. 1983. Diagnostic key for the Neotropical Alticine genera (Coleoptera: Chrysomelidae: Alticinae). Entomologische Arbeiten aus dem Museum G. Frey Tutzing bei München 31/32: 1-89.

Scherer, G. 1989. Ground living flea beetles from the Himalayas (Coleoptera: Chrysomelidae: Alticinae). Spixiana 12(1): 31-55. 